\title{
Cellulose acetate membranes functionalized with resveratrol by covalent immobilization for improved osseointegration
}

A.M. Pandele ${ }^{1,2}$, P. Neacsu ${ }^{3}$, A. Cimpean ${ }^{3}$, A.I. Staras ${ }^{3}$, F. Miculescu ${ }^{4}$, , A. Iordache ${ }^{1}$, S.I.

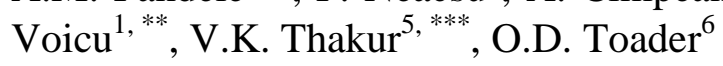

1 University Politehnica from Bucharest, Department of Analytical Chemistry and Environmental Engineering, Str. Gheorghe Polizu 1-7, 011061 Bucharest, Romania, e-mail: svoicu@gmail.com

${ }^{2}$ University Politehnica from Bucharest, Advanced Polymers Materials Group, Str. Gheorghe Polizu 1-7, 011061 Bucharest, Romania

${ }^{3}$ University of Bucharest, Department of Biochemistry and Molecular Biology, Splaiul Independentei 91-95, 050095 Bucharest, Romania

${ }^{4}$ University Politehnica from Bucharest, Metallic Materials Science, Physical Metallurgy Department, Splaiul Independentei 313, 060042 Bucharest, Romania

${ }^{5}$ University of Cranfield, School of Aerospace, Transport and Manufacturing, Cranfield, Bedfordshire MK43 0AL, United Kingdom

${ }^{6}$ Carol Davila University of Medicine and Farmacy, Str. Dionisie Lupu 37, 030167 Bucharest, Romania

*Corresponding author: Florin Miculescu, f_miculescu@yahoo.com

**Corresponding author: Stefan Ioan Voicu, svoicu@gmail.com, stefan.voicu@upb.ro

***CCorresponding author: Vijay Kumar Thakur, Vijay.Kumar@cranfield.ac.uk

\begin{abstract}
Covalent immobilization of resveratrol onto cellulose acetate polymeric membranes used as coating on a $\mathrm{Mg}-1 \mathrm{Ca}-0.2 \mathrm{Mn}-0.6 \mathrm{Zr}$ alloy is presented for potential application in the improvement of osseointegration processes. For this purpose, cellulose acetate membrane is hydrolysed in the presence of potassium hydroxide, followed by covalent immobilization of aminopropyl triethoxy silane. Resveratrol was immobilized onto membranes using glutaraldehyde as linker. The newly synthesised functional membranes were thoroughly characterized for their structural characteristics determination employing X-ray photoelectron spectroscopy (XPS), infrared spectroscopy (FT-IR), Raman spectroscopy, thermogravimetric analysis (TGA/DTG) and scanning electron microscopy (SEM) techniques. Subsequently, in vitro cellular tests were performed for evaluating the cytotoxicity biocompatibility of synthesized materials and also the osseointegration potential of obtained derivatised membrane material. It was demonstrated that both polymeric membranes support viability
\end{abstract}


and proliferation of the pre-osteoblastic MC3T3-E1 cells, thus providing a good protection against the potential harmful effects of the compounds released from coated alloys. Furthermore, cellulose acetate membrane functionalized with resveratrol exhibits a significant increase in alkaline phosphatase activity and extracellular matrix mineralization, suggesting its suitability to function as an implant surface coating for guided bone regeneration.

Keywords: Cellulose acetate membranes, derivatization, osseointegration, resveratrol

\section{Introduction}

Polymeric membranes possess an unique own place in the current materials usage because of their core property - selectivity [1], which allows their use in a large field of applications, such as water purification [2, 3], proteins separation [4], fuel cells [5], or sensors [6-8]. One of the most studied domain is the biomedical applications field, such as haemodialysis and drug controlled release [9] or antimicrobial membranes [10]. Among the different polymers used in membranes applications, cellulose derivatives are among the utmost used polymers because of their wide spread nature (the most abundant material$5 \times 10^{11}$ tones generated in the biosphere in a year [11]), pronounced mechanical properties $[12,13]$, thermal resistance $[14,15]$ and the versatility of processing methods $[16,17]$. A new and diminutive studied field is that of membranes for osteointegration - polymeric membranes favouring the welding of metal or graft implants, defective bones, membranes used especially in dentistry [18]. Membranes for such applications favour the proliferation of osteoblasts from the bone to the metallic implant [19-21], and must also be obtained from biodegradable and bioresorbable polymers [22-24]. The possibility to obtain these materials from biocompatible and bioresorbable polymers such as chitosan [25], collagen [26, 27] cellulose derivatives [28], or caprolactone [29] has been studied in detail. Other studies have been performed on biocompatible, non-biodegradable polymers, but with high capacity for osteointegration such as polytetrafluoroethylene (PTFE) [30]. Different synthetic methods such as precipitation or sol-gel synthesis [31] have also been studied, as well as the possibility of combining membrane osteointegration with controlled release [32, 33].

The present study comes as a continuation of previous research performed by the same team on the synthesis of functionalized membranes with potential for osteointegration, 
the molecule initially studied being sericin [28]. Thus, in this case, cellulose acetate (CA) membrane was functionalized with resveratrol (Res), a natural polyphenolic compound that has been shown to have a stimulatory effect on bone formation both in vitro $[34,35]$ and in vivo [36].

In vitro studies are often performed in order to assess the bioactvity of a material used as potential candidate for bone tissue engineering [34][37]. Bone formation involves active and differentiated osteoblaststs which induce the synthesis of extracellular matrix that will support the mineralization process [35][38]. This natural function of osteoblasts might be influenced by the presence of a degradable implant [36][39]. Recent investigations have shown that magnesium ( $\mathrm{Mg}$ ) itself has the capacity to stimulate the osteoblasts and to induce osteoinductive properties [37-40][40-43]. However, the rapid degradation rate of $\mathrm{Mg}$ remains a critical challenge. To prevent the fast dissolution of a $\mathrm{Mg}$ alloy, namely $\mathrm{Mg}-1 \mathrm{Ca}-0.2 \mathrm{Mn}-$ $0.6 \mathrm{Zr}$ alloy, in the present work cellulose acetate (CA) coatings or CA coatings functionalized with resveratrol (CA-Res) are proposed. In vitro tests of cellular proliferation and differentiation are performed in order to evaluate these novel biomaterials for their bone forming potential using MC3T3-E1 cell line. The obtained results could provide additional information for the development of novel materials for application in bone tissue engineering that enhance bone repair and regeneration.

The aim of this paper was to develop a facile method for immobilizing resveratrol (Res) on the surface of a cellulose acetate CA membrane using aminopropyl triethoxysilane (APTS) and glutaraldehyde as linker molecules. The obtained membraness were morphologically and structurally characterized, and cell culture-based tests were also performed to verify the character of osteointegration.

In order to cover the implants made by $\mathrm{Mg}$ alloy, the membrane for coating can be synthesized by dipping the alloy in any shape in polymer solution, followed by solvent evaporation. By solvent evaporation, very compact polymeric films are synthesized with small-diameter pores, conferring a smooth character to the surface. The strength of the coating and also the adhesion is indicated by its block uniformity [44].

\section{Materials and methods}

\subsection{Membranes synthesis}


For the immobilization of resveratrol, the cellulose derivative -cellulose acetate was used. The membranes were prepared using a $12 \%$ cellulose acetate solution (CA, Sigma Aldrich, 67\% acetylation degree) in N, N'-dimethylformamide (DMF, Sigma Aldrich analytical purity 99.96\%). Membranes synthesis was done using inversion of the phase by precipitation in water. For this, a polymer film of $300 \mu \mathrm{m}$ thickness is deposited on the glass and immersed in the clotting bath until the formed membranes detach from the surface of the support. After the membranes are formed, they are washed successively with ultrapure water and ethyl alcohol to remove any solvent.

To modify the membrane surface with APTS and glutaraldehyde, our previously established method was used [28]. For partial membrane hydrolysis, treatment with a $0.1 \mathrm{~N}$ sodium hydroxide solution (Merck) was carried out for 2 hours at $37^{\circ} \mathrm{C}$. The immobilization reaction of APTS was performed in a weak basic catalysis using a sodium hydroxide $(0.1 \mathrm{~N})$ solution ( $2 \mathrm{~mL}$ per membrane) and $20 \mathrm{~mL}$ of $20 \%$ APTS in ultra-pure water for 24 hours at $37{ }^{\circ} \mathrm{C}$. After the completion of the reaction, the membranes were thoroughly washed with deionized water in order to remove any traces of unreacted APTS. For resveratrol immobilization (Sigma Aldrich), glutaraldehyde was used as the linker molecule to cross link the APTS and protein. To this end, 50\% glutaraldehyde $(20 \mathrm{~mL})(\mathrm{GA}$, Fluka) in deionized water together with sodium hydroxide $(2 \mathrm{~mL} ; 0.1 \mathrm{~N})$ solution was added over the membrane with APTS maintaining the reaction temperature for 2 hours at $40^{\circ} \mathrm{C}$. After two hours, membrane was washed and treated with $20 \mathrm{~mL}$ of $1 \%$ resveratrol solution at $37^{\circ} \mathrm{C}$ for 4 hours in deionized water in the presence of sodium hydroxide $(0.1 \mathrm{~N} ; 2 \mathrm{~mL})$ solution. After the completion of the reaction, the membranes were washed and stored in cold ultra-pure water to, so as to avoid the proliferation/ formation of microorganisms on the membrane surface. Fig. 1 shows the schemes of derivatization reactions. For in vitro biological tests, Mg-based alloy discs with thickness of $2 \mathrm{~mm}$ and diameter of $16 \mathrm{~mm}$ were dipped for three times in CA solution. After solvent evaporation at $45^{\circ} \mathrm{C}$ for 72 hours, the polymer film, which coated the alloy, was functionalized by using the same procedures previously described.

\subsection{Membranes characterization}

The synthesized membranes were analysed by Fourier FT-IR using a Bruker Tensor 27 apparatus having a diamond ATR device (range 600-4000 $\mathrm{cm}^{-1}$ ). Different spectra were recorded as an average of 32 successive measurements, eliminating noise bands, atmospheric carbon dioxide and atmospheric water vapor [28]. Scanning electron microscopy (SEM) (FEI XL-30-ESEM TMP instrument) was used to study the membrane morphology. The X-ray 
photoelectron spectroscopy (XPS) analysis was performed on a Thermo Scientific K-Alpha instrument and the TGA analysis was carried out in nitrogen atmosphere (room temperature to $800{ }^{\circ} \mathrm{C}$ ) at a heating rate of $10^{\circ} \mathrm{C} / \mathrm{min}$ on a Q500 TA Instruments[28]. Deconvolutions of the $\mathrm{C} 1 \mathrm{~s}, \mathrm{O} 1 \mathrm{~s}$ peaks were performed after Shirley's inelastic background subtraction and were normalized for the measured transmission function of the spectrometer. A Sartorius installation system was used to study the water flows for the synthesized membranes using $4.5 \mathrm{~cm}$ diameter membrane discs and $500 \mathrm{~mL}$ deionized water (continuous recirculation). The vacuum in the system was always maintained below the being 0.1 bar. All the tests were performed by continuously recirculating the volume of water. For protein retention, analytical grade Bovine serum albumin (BSA, Merck) and Hemoglobin (Merk) were used. They were dissolved in ultrapure water at a concentration of $10^{-5} \mathrm{M}$. A 10 -point calibration curve was used to determine the concentration by measuring UV-Vis protein absorbance. "For this, a Camspec spectrophotometer both in permeate and retentate from 10 to 10 minutes was used and the retention was calculated with the following formula" [28]:

$$
\mathrm{C}(\%)=\frac{\mathrm{Ci}-\mathrm{Cf}}{\mathrm{Ci}} * 100
$$

where $\mathrm{Ci}$ represents the concentration in the permeate, and $\mathrm{Cf}$ represents the concentration of the protein in the retentate.

\subsection{In vitro biological testing}

\subsubsection{Extract preparation and cell culture model}

To perform in vitro tests, cellulose acetate CA membranes and resveratrol Resfunctionalized membranes were immobilized on $\mathrm{Mg}-1 \mathrm{Ca}-0.2 \mathrm{Mn}-0.6 \mathrm{Zr}$ alloy discs with implantable potential, synthesized by the same procedure described above. Due to the fact that Mg-based materials proved to strongly affect osteoblasts viability over time in direct contact experiments (data not shown), in the present study the cellular response was tested using Mg extraction media prepared according to ISO 10993-12 standards [45]. It is worth mentioning that the accumulation of ions and particles released by biodegradable $\mathrm{Mg}$ alloys in the culture medium can kill the cells by osmotic shock in vitro. In in vivo conditions, the corrosion products could be tolerated due to circulatory system of the body. Therefore, to reduce the accumulated $\mathrm{Mg}$ degradation products, extract preparation and direct dilutions of the extracts are more suitable approaches to better mimic the in vivo conditions. The samples were firstly sterilized under ultraviolet light overnight, then immersed for $24 \mathrm{~h}$ at $37^{\circ} \mathrm{C}$ in 
Dulbecco's Modified Eagle's Medium (DMEM), at a ratio of the surface area to the volume of extraction media of $3 \mathrm{~cm}^{2} / \mathrm{ml}$. For further experiments, the medium was collected and diluted (8x) with cell culture media and supplemented with $10 \%$ fetal bovine serum (FBS). It is worth mentioning that artificial ultraviolet light can convert the trans-form of Res into cisisomer, which is extremely sensitive to light having the capacity to convert back to the more stable trans-isomer. In consequence, the in vitro effects could be attributed to both isoforms of the phenolic compound.

For cell-based investigations, MC3T3-E1 subclone 4 murine pre-osteoblast cells (American Type Culture Collection) were used. The cells were routinely cultured in DMEM supplemented with $1 \%$ penicillin/streptomycin and 10\% FBS and incubated in a humidified atmosphere of $5 \% \mathrm{CO}_{2}$ at $37^{\circ} \mathrm{C}$. The medium was changed every 3 days during the incubation period. For further indirect contact experiments, MC3T3-E1 cells were trypsinized at about $80 \%$ confluence and seeded on 12-well-plates in the corresponding extraction media. In order to perform the studies of cell adhesion, morphology and proliferation capacity an initial density of $1.5 \times 10^{4}$ cells $/ \mathrm{cm}^{2}$ was used. The effects of the sample extracts on the preosteoblast differentiation were assessed using an initial density of $4 \times 10^{4}$ cells $/ \mathrm{cm}^{2}$ in the absence or in the presence of osteoinductive agents $(50 \mu \mathrm{g} / \mathrm{ml}$ ascorbic acid and $5 \mathrm{mM} \beta$ glycerophosphate).

\subsubsection{Evaluation of cell attachment and morphology}

Cells that were cultured in 24-well-plates in the corresponding extraction media were subjected to immunocytochemistry studies in order to highlight the adhesion capacity after 2 $\mathrm{h}$ and the organization of actin cytoskeleton after $24 \mathrm{~h}$ of incubation. Briefly, the cells were fixed with cold $4 \%$ paraformaldehyde for $30 \mathrm{~min}$ at $25^{\circ} \mathrm{C}$. After three washes with phosphatebuffered saline (PBS), the cells were permeabilized using a solution that contained Triton X$100(0.1 \%)$ and bovine serum albumin (2\%). Actin filaments and vinculin were stained using Alexa Flour-488 phalloidin (Life Technologies, USA) and anti-vinculin antibody (Santa Cruz Biotechnology) followed by Alexa Fluor 546-conjugated secondary antibody (Life Technologies, USA) as previously described [46]. Cells were visualized using a fluorescence microscope (Olympus IX71) and representative images were captured using Cell-F image acquiring system.

\subsubsection{Cell proliferation assessment}


The potential cytotoxicity of the extracts was tested using MTT (3- (4, 5-dimethylthiazol-2-yl) -2, 5-diphenyltetrazolium bromide) method. Before performing the test, the extraction media were replaced with fresh culture media to avoid any interference of the tetrazolium salt with compounds released from the Mg-based alloy [47]. The proliferative capacity of the cells was assessed at 1, 3 and 5 days post-seeding in the corresponding extraction media, as described previously [46].

\subsubsection{Alkaline phosphatase quantification}

After growing the MC3T3-E1 cells in the Mg alloy extracts for 7 and 14 days, the alkaline phosphatase (ALP) activity was measured employing a commercial kit (Alkaline Phosphatase Activity Colorimetric Assay Kit, BioVision). Thus, at the studied time points, cells were thoroughly washed with PBS and lysed using a lysis buffer provided by the kit. The lysates were then centrifuged to eliminate the cellular debris. For the assay, $80 \mu \mathrm{l}$ of supernatant containing the enzyme were used and then $50 \mu \mathrm{l}$ of $5 \mathrm{mM}$ nitrophenylphosphate (pNPP) was added and incubated for $60 \mathrm{~min}$ at $25^{\circ} \mathrm{C}$ in the dark. The optical density was measured at $405 \mathrm{~nm}$ using a microplate reader (Thermo Scientific Appliskan). After calculating the concentration of the reaction product by relating to a standard curve, the values were normalized to $1 \mathrm{mg} / \mathrm{ml}$ protein. The overall protein content for each sample was previously determined using Bradford reaction. Subsequently, the ALP activity was calculated using the formula: ALP activity $(\mathrm{U} / \mathrm{ml})=\mathrm{A} / \mathrm{V} / \mathrm{T}$, where $\mathrm{V}$ is the volume of cell lysate used in the reaction (in $\mathrm{ml}$ ), A represents the amount of p-nitrophenol (pNP) expressed by the samples (in $\mu \mathrm{mol}$ ) and $\mathrm{T}$ is the reaction time (in min).

\subsubsection{Extracellular matrix mineralization}

Calcium deposition was evaluated using the Alizarin red staining. Mg alloy extraction media was used to culture the MC3T3-E1 pre-osteoblasts for 4 and 6 weeks under standard and osteogenic culture conditions. At the end of the experimental period, the cells were twice washed with PBS and fixed with paraformaldehyde (10\%) for $20 \mathrm{~min}$ at $25^{\circ} \mathrm{C}$. Then, a staining with Alizarin Red (Sigma) solution was performed at room temperature for 60 minutes. The dye was discarded and the cell monolayer was subsequently washed with distilled water. The calcium deposits were dissolved in 5\% perchloric acid for $10 \mathrm{~min}$. The resulted reaction product was measured at $405 \mathrm{~nm}$ wavelength using the microplate reader (Thermo Scientific Appliskan). 


\subsection{Statistical analysis}

In order to define the statistical importance of differences amid the samples, all data were submitted to one-way analysis of variance ANOVA (Bonfferoni's multiple comparison test). For each sample group, the mean $\pm \mathrm{SD}$ was determined and differences with $\mathrm{p} \leq 0.05$ had been considered to be statistically significant.

\section{Results and discussions}

\subsection{Cellulose acetate-based membrane characteristics}

Recently, magnesium and its alloys have been considered ideal candidates as temporary implants due to their excellent particularities such as strength and ductility and the capability to degrade. However, the main drawback of $\mathrm{Mg}$-based materials is its corrosion resistance which often led to local alkalization and a high amount of hydrogen and other ions accumulation in the cavity around the implant resulting in a rapid loss of the mechanical integrity. In order to overcome these side effects, special alloy designs and surface modifications are required. To obtain better performance of $\mathrm{Mg}$-based implants, this study proposes a newly developed $\mathrm{Mg}-1 \mathrm{Ca}-0.2 \mathrm{Mn}-0.6 \mathrm{Zr}$ alloy coated with a $\mathrm{CA}$ membrane functionalized with Res.

Initial research was performed by the same team that was aimed at deriving the titanium used in implantology with APTS and ethanolamine for further osteointegration of membranes for osteointegration applications [27]. The reason for choosing cellulose acetate for the present study was that by the hydrolysis and degradation in the biological environment, the major compound that is released is glucose. Another advantage would be that, despite biocompatibility, cellulose is a hard-to-handle polymer, being soluble only in mixtures of very toxic organic compounds. While, an inconvenience would be that besides glucose, depending on the degree of acetylation of the polymer, the acetate is released into the body by accepting a proton that can slightly lower the $\mathrm{pH}$ in the body at the site of implantation [28]. Scanning electron microscopy (Fig. 2) reveals the surface changes for each synthesis step. After treatment of the membranes with sodium hydroxide, a surface relaxation was observed because simultaneously with the hydrolysis reaction and the release of the acetate groups, the local breakage of some polymer chains occurs. After immobilisation of APTS, it has a crosslinking effect and consequently a decrease in membrane porosity is observed. The effect has become more pronounced in the case of glutaraldehyde membranes, 
but decreases for membranes with resveratrol immobilized due to the effect of hydrolysis and breaking of glutaraldehyde molecules to immobilize resveratrol. These changes have been also visible on the porous surface of the membranes. However, these are not so pronounced due to both the large pore size and the fact that this surface has been masked by the glass substrate that has been subjected to the derivatization reactions. Despite the fact that glutaraldehyde is a toxic compound, after functionalization, initial carbonyl groups are transformed. Due to these modifications, by membrane decomposition it is impossible the release of the toxic form of glutaraldehyde.

The conclusions obtained from the interpretation of the electronic microscopy analysis were further supported by the thermal analysis (Fig. 3). If cellulose acetate membranes are considered as a standard, a decrease of DTG from $345^{\circ} \mathrm{C}$ in the CA membrane at $327^{\circ} \mathrm{C}$ is observed for CA-APTS-GA-RES membrane. For CA-APTS and CAAPTS-GA membranes, the DTG value is comparable to that of CA, this being explained by the fact that at the same time with the immobilization of APTS and GA, there has been also a partial hydrolysis of the polymer. Practically, the needles are gained in the thermal resistance of the polymer by cross-linking the surface of the membrane, thereby losing hydrolysis. In the CA-APTS-GA-RES membrane, with the breakdown of GA molecules for surface derivatisation with resveratrol, the effect of lowering the thermal resistance becomes significant, thus obtaining the difference between the two values (CA versus CA-APTS- GARES) (Table 1).

In the FT-IR spectrum of cellulose acetate (Fig. 4), the peaks attribution is as follows: $1700 \mathrm{~cm}^{-1}$ for the $-\mathrm{COO}$ groups, $1250 \mathrm{~cm}^{-1}$ for the $\mathrm{CO}$ groups, $1050 \mathrm{~cm}^{-1}$ for the deformation vibrations of the bonds of the $\mathrm{CH}$ and $\mathrm{OH}$ groups, $900 \mathrm{~cm}^{-1}$ for the deformation vibrations of the $\mathrm{COC}, \mathrm{CCO}$ and $\mathrm{CCH}$ groups [48]. It can be observed that for the $-\mathrm{C}-\mathrm{H}$ bands of membranes derivatised with APTS and GA, the peaks move to the left confirming the complete modification of the form for the membrane CA-APTS-GA-RES. Also, for the CAAPTS-GA-RES membrane, the $1250 \mathrm{~cm}^{-1}$ band specifies the $\mathrm{CO}$ groups in the acetate residues disappearance, indicating a high degree of functionalization of the membrane. The spectrum of the CA-APTS-GA-RES membrane is also different from the other membranes, but the presence of resveratrol can be identified but without much influence due to its small percentage of the surface compared to the polymer-specific groups (Fig. 4). Modifications in $3000-3500 \mathrm{~cm}^{-1}$ range of FT-IR can be attributed to the hydrophilicity of membranes, since this region indicate the presence of hydrogen bonds from water. With the increase of 
functionalization degree on surface and also with the increase of compactness of membrane, the material surface become more and more swelled with water molecules. More than that, the highest intensity (if we consider as etalon peak, for example $1050 \mathrm{~cm}^{-1}$ ) is presented for CA-APTS-GA-RES and can be explained by the hydrophilicity of the protein.

XPS spectra (Fig. 5) do not show substantial changes between synthesized materials, primarily because of the large amount of polymer that predominates in the structure of each material. In case of CA-APTS, CA-APTS-GA, CA-APTS-GA-RES membranes, the Si atoms (at $100 \mathrm{eV}$ ), respectively nitrogen at $400 \mathrm{eV}$, are observed. Also, for the CA-APTS-GA-RES membrane, oxygen (at $540 \mathrm{eV}$ ) has the highest intensity if we take the carbon band as the reference due to the presence of the three hydroxyl group groups remaining free on the surface of the material. This observation is consistent with observations made on FT-IR spectra on large surface substitution radar.

In order to prove the functionalization of $\mathrm{CA}$, the $\mathrm{C}$ 1s (Fig.6) and $\mathrm{O} 1 \mathrm{~s}$ (Fig. 7) high resolution spectra were recorded for all the samples. According to figure 6, C1s spectrum displays five different peaks located at 281, 286, 284, 288 and $287 \mathrm{eV}$ attributed to $\mathrm{C}=\mathrm{O}, \mathrm{C}$ $\mathrm{O}, \mathrm{C}-\mathrm{C}, \mathrm{C}-\mathrm{N}$ and C-O phenolic [49-51]. The first step of CA functionalization has been made to increase the number of $\mathrm{OH}$ available groups on $\mathrm{CA}$ surface and this could be observed by an increase of the intensity ratio between $\mathrm{C}-\mathrm{O}$ and $\mathrm{C}-\mathrm{C}\left(\mathrm{I}_{\mathrm{C}-\mathrm{O}} / \mathrm{I}_{\mathrm{C}-\mathrm{C}}\right)$ in the $\mathrm{C} 1 \mathrm{~s}$ spectra of CA$\mathrm{OH}$. The next step of functionalization (reaction with GA) was demonstrated by the presence of a new peak at $288 \mathrm{eV}$ which is assigned to $\mathrm{C}-\mathrm{N}$ from GA. Resveratrol immobilization was demonstrated by the appearance of phenolic oxygen peak at $287 \mathrm{eV}$ and also by the shifting of this peak to a lower level. A more detailed discussion can be made on $\mathrm{O}$ 1s highresolution spectra. In addition, $\mathrm{O} 1 \mathrm{~s}$ spectrum (Fig.7) can be deconvoluted to four peak centered at 533, 531, 529 and $536 \mathrm{eV}$ assigned to $\mathrm{OH}, \mathrm{C}=\mathrm{O}, \mathrm{Si}-\mathrm{O}$ and $\mathrm{C}-\mathrm{O}$ phenolic respectively [49-51]. After the initial hydrolysis of CA the highest intensity of C-O peak (in $\mathrm{CA}-\mathrm{OH}$ spectra) suggest the increasing of HO groups. In the case of CA-APTS, the appearance of $\mathrm{SiO}$ specific peak suggests the immobilization at the surface of membrane of APTS. A discussion regarding C-O intensity cannot be made for CA-APTS due to high steric distribution of other functional groups. In the spectra of CA-APTS-GA-Res the peak at 536 $\mathrm{eV}$ attributed to $-\mathrm{O}-\mathrm{C}_{6} \mathrm{H}_{5}$ from resveratrol appears and also a high intensity of $\mathrm{C}-\mathrm{O}$ is observed which is the linker group of resveratrol for the rest of molecular assembly.

From the point of view of the retentive capacity of the developed membranes, retention of bovine serum albumin and haemoglobin was studied (Fig. 8). The peak retention in both these materials was attributed to the surface immobilization of resveratrol on the 
membranes (85\% retention for BSA, respectively $90 \%$ for hemoglobin, after 2 hours of recirculation of the feed solution). This behaviour is explained by the affinity of the functional groups of the protein for the functional groups of resveratrol (hydroxyl) and the very low porosity on the membrane filter surface. Also, due to good initial retention, subsequent growth is attributed to the protein-protein associations at the surface of the membrane. For membranes with APTS and GA immobilized on the surface, the retention is quite comparable. The higher degree being explained by the low porosity as compared to that of the cellulose acetate control membrane [28]. The higher retention for hemoglobin is primarily due to its larger molecule, which on accumulates at the filter surface allows less and less passage of the same species through the membrane structure.

The water flows (Fig. 9) results obtained for the developed membranes are in confirmation with the rest of the performed analyses. Taking cellulose acetate membrane as standard with an average flow of approximately $9847 \mathrm{~L} / \mathrm{m}^{2} \mathrm{~h}$, decreasing trend in CA-APTS, CA-APTS-GA, CA-APTS-GA-RES membranes (9600, 9021 and $8435 \mathrm{~L} / \mathrm{m}^{2} \mathrm{~h}$, respectively) have been observed due to decreased porosity and crosslinking effect attributed to the reactions on the surface. Also, the decrease of water flow in the case of CA-APTS-GA-RES can be also attributed to the cover of surface with protein.

\subsection{In vitro biological performance of cellulose acetate coated $\mathrm{Mg}-1 \mathrm{Ca}-0.2 \mathrm{Mn}-0.6 \mathrm{Zr}$ alloy}

To investigate the potential effects of Mg-CA and Mg-CA-Res extraction media on MC3T3-E1 pre-osteoblasts behaviour, indirect contact tests using extraction media harvested from each sample were performed in order to examine cell adhesion, organization of the cytoskeleton, proliferation capacity and differentiation potential. Fig. 10 shows the preosteoblast capacity to adhere and grow in the presence of these extraction media. Initial cell adhesion was reported to play a major role in stimulating signals that regulate cell differentiation, cell cycle, cell migration and cell survival [52]. Thus, indirect cell adhesion experiments performed after $2 \mathrm{~h}$ of culture revealed efficient osteoblasts attachment and distribution in both extraction media with no obvious differences. After $24 \mathrm{~h}$ of culture, fluorescent images showed that the cells were allowed to normally grow in the two tested media, exhibiting typical cuboidal and spindle-shaped morphologies and numerous focal adhesion sites. These observations suggest that the compounds released from the two materials did not significantly affect the actin cytoskeleton of osteoblasts or the focal adhesion structures as highlighted by vinculin staining. Moreover, at $24 \mathrm{~h}$ post-seeding, an 
increased cell density could be remarked in the case of both $\mathrm{Mg}$ alloy extracts meaning that cell proliferation was promoted.

Further on, the proliferative status of MC3T3-E1 cells was assessed by performing the MTT assay. Data obtained in this study confirm that the two materials do not exert deleterious effects on cells (Fig. 11) suggesting that both CA-based membranes ensures a good protection against the potential harmful effects of the compounds released from $\mathrm{Mg}$ alloy. As it is shown in the graph, the O.D. values increased along with the incubation period from day 1 to day 5. These results demonstrate that $\mathrm{Mg}-\mathrm{CA}$ and $\mathrm{Mg}$-CA-Res extracts allow the proliferation of osteoblasts in a similar manner over the first 3 days of cell incubation. However, after 5 days of culture a slight reduction of the number of metabolically active cells was recorded in the case of $\mathrm{Mg}-\mathrm{CA}-\mathrm{Res}$ as compared to $\mathrm{Mg}-\mathrm{CA}$ sample. These preliminary indirect contact studies indicate that $\mathrm{Mg}$ alloys coated with $\mathrm{CA}$ and $\mathrm{CA}-\mathrm{Res}$ could represent biocompatible materials in terms of cell adhesion and proliferation of MC3T3-E1 preosteoblasts.

The complex process of bone formation involves three major stages namely proliferation, extracellular matrix maturation and mineralization [53]. ALP activity and extracellular matrix mineralization are two markers frequently used for detecting early and late differentiation of osteoblasts [54]. The influence of the compounds released from $\mathrm{Mg}-\mathrm{CA}$ and Mg-CA-Res biomaterials on ALP activity was assessed after 7 and 14 days of culture in two experimental conditions, namely in standard or osteoinductive environment. Fig. 9A presents the evolution of ALP activity, normalized to total protein content, expressed by MC3T3-E1 cells grown in the tested extraction media. The results obtained show an increase in ALP activity from day 7 to day 14 and under osteogenic inducing culture conditions. Furthermore, after 7 days of culture no significant differences in the expression of ALP activity by the cells grown in the coated $\mathrm{Mg}$ alloy extraction media in both experimental culture conditions were remarked. However, MC3T3-E1 cells cultured for 14 days in the presence of Mg-CA-Res extraction medium exhibited significantly higher levels of ALP activity $(\mathrm{p}<0.05)$ when compared with $\mathrm{Mg}-\mathrm{CA}$ extraction media in both experimental conditions. These observations indicate that the functionalization of CA coating with Res can better stimulate osteoblast cell differentiation. In cell culture-based studies of osteogenic differentiation, extracellular matrix mineratization is considered a functional endpoint which reflects advanced osteoblast differentiation [55]. In this investigation, the formation of calcium deposits was determined by Alizarin red staining. Fig. 11 shows that the addition of 
osteoinductive factors lead to a slight increase of the absorbance values corresponding to the analysed samples after 4 and 6 weeks of cell culture. Although at the studied time points only a vague mineral accumulation was noticed, when MC3T3-E1 cells were cultured in Mg-CARes extraction medium, the calcium nodules were stained intensively with Alizarin red and increased visibly (data not shown). Quantitative evaluation of the degree of matrix mineralization revealed that calcium nodule formation was significanlty enhanced when the cells were cultured in the extraction media of Mg-CA-Res supplemeted with osteogenic factors both after $4(\mathrm{p}<0.05)$ and 6 weeks $(\mathrm{p}<0.001)$ as compared with the unfunctionalized sample. These observations indicate that the MC3T3-E1 cells which presented significant ALP activity were able to induce an increased degree of matrix mineralization, suggesting a close relation between these two markers of osteoblast differentiation. Consequently, our results show that Res covalently bonded to CA particles released in the culture media as a result of the degradability potential of CA material [56] could have a significant effect on the bone mineralization process. Moreover, as mentioned in the discussion section of the manuscript, a number of studies indicated that Res improves the obsteoblasts functionality, including the differentiation and mineralization potential. These data are supported by the recent findings which indicate that this biomolecule holds the potential to enhance osteoblast functionality. Thus, Tseng et al. [57] found that Res promoted spontaneous osteogenesis upregulating the expression of osteolineage genes RUNX2 and osteocalcin. Likewise, it was shown that Res activated sirtuin-1 (Sirt-1) plays pivotal roles in regulating the balance between osteoclastic and osteoblastic activities leading to increased bone formation in vitro [58]. Other studies that investigated the possibility of incorporating Res onto different scaffolds also showed a positive impact of this compound on bone mineralization. Thus, Kamath et al. [59] demonstrated that Res-loaded albumin nanoparticles into a polycaprolactone scaffold significantly improved mineralization due to prolonged release of Res. Likewise, incoporation of Res into an acrylic acid-functionalized porous poly- $\varepsilon^{-}$ caprolactone led to a significant increase in osteogenesis [60]. Moreover, due to the fact that CA is a semipermeable membrane [61], it does not create a perfect barrier for $\mathrm{Mg}^{2+}$ and $\mathrm{H}_{2}$ gas. Even though the $\mathrm{Mg}$ alloy is coated with the CA membrane, the dissolution of $\mathrm{Mg}$ alloy occurs and the corrosion products are accumulated between the membrane and the sample. However, in case of $\mathrm{Mg}-\mathrm{CA}$ sample the transport of these products is limited to a certain extent. As a consequence, a low amount of $\mathrm{Mg}^{2+}$ could be released in the culture media during the extraction time. The products released by natural degradation of $\mathrm{Mg}$ alloys were shown to induce proliferation and differentiation of normal human osteoblasts [62]. 
Therefore, the combination of both $\mathrm{Mg}^{2+}$ ions and the particles containing the phenolic compound could facilitate the overall osteoblast mineralization in a synergistic way.

\section{Conclusions}

Covalent immobilization of resveratrol Res onto cellulose acetate CA polymeric membranes was presented for potential application in the improvement of osseointegration processes. Resveratrol was immobilized onto membranes using glutaraldehyde as linker after initial reaction between hydrolysed cellulose acetate and amino propyl triethoxy silane. Scanning electron microscopy revealed morphological changes (due to the crosslinking effect of APTS and glutaraldehyde reactions), correlated with water flows through synthesized membranes and proteins retention. Covalent immobilization of reseveratrol Res was proved by FT-IR, XPS and thermal analysis. In vitro results obtained by performing indirect contact experiments of MC3T3-E1 cells with $\mathrm{Mg}-1 \mathrm{Ca}-0.2 \mathrm{Mn}-0.6 \mathrm{Zr}$ alloy coated with CA or CA-Res showed good osteoblasts viability and differentiation potential in terms of ALP activity and bone mineralization. Furthermore, the functionalization of CA membrane with resveratrol Res led to a significant increase in ALP activity and extracellular matrix mineralization suggesting its adequacy to be used as a way of modifying implant surface in order to guide bone regeneration

\section{Acknowledgement}

The authors gratefully acknowledge the financial support through project PN II-PTPCCA-195/2014, acronym BioCoatMag, financed by the Romanian Ministry of National Education, CNCS - UEFISCDI Romania.

\section{REFERENCES}

[1] M. Ulbricht, Advanced functional polymeric membranes, Polymer, 47(7) (2006) 22172262.

[2] S.I. Voicu, C.M. Ninciuleanu, O. Muhulet, M. Miculescu, Cellulose acetate membranes with controlled porosity and their use for the separation of aminoacids and proteins, Journal of Optoelectronics and Advanced Materials,16(7-8) (2014) 903-908. 
[3] M. Ionita, L.E. Crica, S.I. Voicu, A.M. Pandele, H. Iovu, Fabrication of Cellulose Triacetate/Graphene Oxide Porous Membrane, Polymers for Advanced Technologies, 27(3) (2016) 350-357.

[4] S.I. Voicu, A. Dobrica, S. Sava, A. Ivan, L. Naftanaila, Cationic surfactants-controlled geometry and dimensions of polymeric membrane pores, Journal of Optoelectronics and Advanced Materials, 14(11-12) (2012) 923-928.

[5] M. Ionita, E. Vasile, L.E. Crica, S.I. Voicu, A.M. Pandele, S. Dinescu, L. Predoiu, B. Galateanu, A. Hermenean, M. Costache, Synthesis, characterization and in vitro studies of polysulfone/graphene oxide composite membranes, Composites Part B, 72 (2015) 108-115

[6] M. Ionita, G.M. Vlasceanu, A.A. Watzlawek, S.I. Voicu, J.S. Burns, H. Iovu, Graphene and functionalized graphene: Extraordinary prospects for nanobiocomposite materials, Composites Part B, 2017, DOI: http://dx.doi.org/10.1016/j.compositesb.2017.03.031

[7] S.I. Voicu, M.A. Pandele, E. Vasile, R. Rughinis, L. Crica, L. Pilan, M. Ionita The impact of sonication time through polysulfonegraphene oxide composite films properties, Digest Journal of Nanomaterials and Biostructures, 8(4) (2013) 1389-1394

[8] M. Miculescu, V.K. Thakur, F. Miculescu, S.I. Voicu, Graphene based polymer nanocomposite membranes: A Review, Polymers for Advanced Technologies, 27(7) (2016) 844-859

[9] D.F. Stamatialis, B.J. Papenburg, M. Gironès, S. Saiful, N.M.S. Bettahalli, S. Schmitmeier, M. Wessling, Medical applications of membranes: Drug delivery, artificial organs and tissue engineering, Journal of Membrane Science, 308 (2008) 1-34.

[10] E. Rusen, A. Mocanu, L.C. Nistor, A. Dinescu, I. Călinescu, G. Mustăţea, Ş.I. Voicu, C. Andronescu, A. Diacon, New design of antimicrobial membranes based on polymers colloids/MWCNT hybrid materials and silver nanoparticles, ACS Applied Materials and Interfaces, 6(20) (2014) 17384-17393.

[11] V.K. Thakur, S.I. Voicu, Recent Advances in Cellulose and Chitosan Membranes for Water Purification: A Concise Review, Carbohydrate Polymers, 146 (2016) 148-165;

[12] V.K. Thakur, M.R. Kessler, Self-healing polymer nanocomposite materials: a review. Polymer, 69 (2015) 369-383.

[13] M.K. Thakur, R.K. Gupta, V.K. Thakur, Surface modification of cellulose using silane coupling agent. Carbohydrate Polymers, 111 (2014) 849-855.

[14] V.K. Thakur, M.K. Thakur, M. K. Processing and characterization of natural cellulose fibers/thermoset polymer composites. Carbohydrate Polymers, 109 (2014) 102-117. 
[15] V.K. Thakur, M.K. Thakur, R.K. Gupta, Rapid synthesis of graft copolymers from natural cellulose fibers. Carbohydrate Polymers, 98(1) (2013) 820-828.

[16] V.K. Thakur, D. Vennerberg, M.R. Kessler, Green aqueous surfacemodification of polypropylene for novel polymer nanocomposites. ACS Applied Materials \& Interfaces, 6(12) (2014) 9349-9356.

[17] V.K. Thakur, A.S. Singha, B.N. Misra, Graft copolymerization of methylmethacrylate onto cellulosic biofibers. Journal of Applied Polymer Science, 122(1) (2011) 532-544.

[18] S.P. Pilipchuk, A.B. Plonka, A. Monje, A.D. Taut, A. Lanis, B. Kang, W.V. Giannobile, Tissue engineering for bone regeneration and osseointegration in the oral cavity, Dental Materials 31 (2015) 317-338

[19] J. Raphel, M. Holodniy, S.B. Goodman, S.C. Heilshorn, Multifunctional coatings to simultaneously promote Osseointegration and prevent infection of orthopaedic implants, Biomaterials 84 (2016) 301-314.

[20] R. Agarwal, A.J. García, Biomaterial strategies for engineering implants for enhanced osseointegration and bone repair, Advanced Drug Delivery Reviews 94 (2015) 53-62

[21] R. Tejero, E. Anitua, G. Orive, Toward the biomimetic implant surface: Biopolymers on titanium-based implants for bone regeneration, Progress in Polymer Science 39 (2014) 14061447

[22] Y. Liu, J. Lim, S.-H. Teoh, Review: Development of clinically relevant scaffolds for vascularised bone tissue engineering, Biotechnology Advances 31 (2013) 688-705.

[23] R.A. Gittens, L. Scheideler, F. Rupp, S.L. Hyzy, J. Geis-Gerstorfer, Z. Schwartz, B.D. Boyan, A review on the wettability of dental implant surfaces II: Biological and clinical aspects, Acta Biomaterialia 10 (2014) 2907-2918.

[24] S.P. Victor, J. Muthu, Bioactive, mechanically favorable, and biodegradable copolymer nanocomposites for orthopedic applications, Materials Science and Engineering C 39 (2014) $150-160$.

[25] A. Anitha, S. Sowmya, P.T. Sudheesh Kumar, S. Deepthi, K.P. Chennazhi, H. Ehrlich, M. Tsurkan, R. Jayakumar, Chitin and chitosan in selected biomedical applications, Progress in Polymer Science 39 (2014) 1644-1667

[26] H.H. Hirata, M.A.S. Munhoz, A.M.G. Plepis, V.C.A. Martins, G.R. Santos, E.A. Galdeano, M.R. Cunha, Feasibility study of collagen membranes derived from bovine pericardium and intestinal serosa for the repair of cranial defects in ovariectomised rats, Injury, Int. J. Care Injured 46 (2015) 1215-1222 
[27] M.S. Corobea, M.G. Albu, R. Ion, A. Cimpean, F. Miculescu, I.V. Antoniac, V. Raditoiu, I. Sirbu, M. Stoenescu, S.I. Voicu, M.V. Ghica, Advanced modification of titanium surface with collagen and doxycycline, a new approach in dental implants, Journal of Adhesion Science and Technology, 29(23) (2015) 2537-2550.

[28] S.I. Voicu, R.M. Condruz, V. Mitran, A. Cimpean, F. Miculescu, C. Andronescu, M. Miculescu, V.K. Thakur, Sericin Covalent Immobilization onto Cellulose Acetate Membranes, ACS Sustainable Chemistry and Engineering, 4(3) (2016) 1765-1774.

[29] Joshua R. Porter, Andrew Henson, Ketul C. Popat, Biodegradable poly(3-caprolactone) nanowires for bone tissue engineering applications, Biomaterials 30 (2009) 780-788.

[30] S. Suzukia, L. Grøndahl, D. Leavesley, E. Wentrup-Byrne, In vitro bioactivity of MOEP grafted PTFE membranes for craniofacial applications, Biomaterials 26 (2005) 5303-5312.

[31] G.J. Owens, R.K. Singh, F. Foroutan, M. Alqaysi, C.-M. Han, C. Mahapatra, H.-W. Kim, J.C. Knowles, Sol-gel based materials for biomedical applications, Progress in Materials Science 77 (2016) 1-79

[32] A.I. Leal, S.G. Caridade, J. Ma, N. Yu, M.E. Gomes, R.L. Reis, J.A. Jansen, X.F. Walboomers, J.F. Mano, Asymmetric PDLLA membranes containing Bioglass $®$ for guided tissue regeneration: Characterization and in vitro biological behaviour, Dental Materials 29 (2013) 427-436

[33] K. Jamuna-Thevi, M.J. Suleiman, S.N. Sabri, Strength improvement of a functionally graded and layered composite membrane for guided bone regeneration in orthopaedics, Materials Today: Proceedings 3S ( 2016 ) S120 - S128.

[34] K. Mizutani, K. Ikeda, Y. Kawai, Y. Yamori, Resveratrol stimulates the proliferation and differentiation of osteoblastic MC3T3-E1 cells, Biochem. Biophys. Res. Commun. 253 (1998) 859-863.

[35] Z. Dai, Y. Li, L.D. Quarles, T. Song, W. Pan, H. Zhou, Z. Xiao, Resveratrol enhances proliferation and osteoblastic differentiation in human mesenchymal stem cells via ERdependent ERK1/2 activation, Phytomedicine 14 (2007) 806-814.

[36] T. Uysal, S. Gorgulu, A. Yagci, Y. Karslioglu, O. Gunhan, D. Sagdic, Effect of resveratrol on bone formation in the expanded inter-premaxillary suture: early bone changes. Orthodont. Craniofac. Res. 14 (2011) 80-87.

[37] S. Kumar, K. Chatterjee, Strontium eluting graphene hybrid nanoparticles augment osteogenesis in a 3D tissue scaffold, Nanoscale 7 (2015) 2023-2033. 
[38] M.M. Beloti , A.L. Rosa, Osteoblast differentiation of human bone marrow cells under continuous and discontinuous treatment with dexamethasone, Braz. Dent. J. 16 (2005) 156161.

[39] N.A. Agha, R. Willumeit-Römer, D. Laipple, B. Luthringer, F. Feyerabend, The degradation interface of magnesium based alloys in direct contact with human primary osteoblast cells, Plos One 11 (2016) e0157874.

[40] D. Hong, P. Saha, D.T. Chou, B. Lee, B.E. Collins, Z. Tan, Z. Dong, PN Kumta, In vitro degradation and cytotoxicity response of $\mathrm{Mg}-4 \% \mathrm{Zn}-0.5 \% \mathrm{Zr}$ (ZK40) alloy as a potential biodegradable material, Acta Biomater. 9 (2013), 8534-8547.

[41] L. Weng, T.J. Webster, Nanostructured magnesium has fewer detrimental effects on osteoblast function, Int. J. Nanomed. 8 (2013) 1773-1781.

[42] R.M. Lozano, B.T. Perez-Maceda, M. Carboneras, E. Onofre-Bustamante, M.C. GarciaAlonso, M.L. Escudero, Response of MC3T3-E1 osteoblasts, L929 fibroblasts, and J774 macrophages to fluoride surface-modified AZ31 magnesium alloy, J. Biomed. Mater. Res. 101 (2013) 2753-2762.

[43] A. Burmester, R. Willumeit-Romer, F. Feyerabend, Behavior of bone cells in contact with magnesium implant material. J. Biomed. Mater. Res. Part B Appl. Biomater. 105 (2017), 165-179.

[44] P. Neacsu, A.I. Staras, S.I. Voicu, I. Ionascu, T. Soare, S. Uzun, V.D. Cojocaru, A.M. Pandele, S.M. Croitoru, F. Miculescu, C.M. Cotrut, I. Dan, A. Cimpean, Characterization and In Vitro and In Vivo Assessment of a Novel Cellulose Acetate-Coated Mg-Based Alloy for Orthopedic Applications, Materials, 2017, 10, 686; doi:10.3390/ma10070686.

[45] A Practical Guide to ISO 10993-12: Sample Preparation and Reference Materials, 1998.

[46] R. Ion, D.M. Gordin, V. Mitran, P. Osiceanu, S. Dinescu, T. Gloriant, A. Cimpean, In vitro bio-functional performances of the novel superelastic beta-type Ti-23Nb-0.7Ta-2Zr0.5N alloy, Mater. Sci. Eng. C Mater. Biol. Appl. 1 (2014) 411-419.

[47] Fischer J, Prosenc MH, Wolff M, Hort H, Willumeit R, Feyerabend F. Interference of magnesium corrosion with tetrazolium-based cytotoxicity assays. Acta Biomaterialia 6 (2010), 1813-1823.

[48] S. Hokkanen, A. Bhatnagar, E. Repo, S. Lou, M. Sillanpaa, Calcium hydroxyapatite microfibrillated cellulose composite as a potential adsorbent for the removal of $\mathrm{Cr}$ (VI) from aqueous solution, Chem. Eng. J. 283 (2016) 445-452. 
[49] Martina Cazzola, Ingrid Corazzari, Enrico Prenesti, Elisa Bertonea, Enrica Vernè,Sara Ferraris, Bioactive glass coupling with natural polyphenols: Surfacemodification, bioactivity and anti-oxidant ability, Applied Surface Science 367 (2016) 237-248;

[50] Xin Zhang, Sara Ferraris, Enrico Prenesti, Enrica Verné, Surface functionalization of bioactive glasses with natural moleculesof biological significance, part II: Grafting of polyphenolsextracted from grape skin, Applied Surface Science 287 (2013) 341-348;

[51] Sara Ferraris, Xin Zhang, Enrico Prenesti, Ingrid Corazzari, Francesco Turci, Maura Tomatis, Enrica Vernè, Gallic acid grafting to a ferrimagnetic bioactive glass-ceramic, Journal of Non-Crystalline Solids 432 (2016) 167-175

[52] S. Huang, D.E. Ingber, The structural and mechanical complexity of cell-growth control, Nat. Cell Biol. 1 (1999), 131-138.

[53] J.H. Lee, Y.C. Shin, S.M. Lee, O.S. Jin, S.H. Kang, S.W. Hong, C.M. Jeong, J.B. Huh, D.W. Han, Enhanced osteogenesis by reduced graphene oxide/hydroxyapatite nanocomposites, Sci. Rep. 5 (2015) 18833.

[54] Y. Chen, Z. Huang, X. Li, S. Li, Z. Zhou, Y. Zhang, Q. Feng, B. Yu, In vitro biocompatibility and osteoblast differentiation of an injectable chitosan/nanohydroxyapatite/collagen scaffold, J. Nanomat. (2012), Article ID 401084.

[55] C.D. Hoemann, H. El-Gabalawy, M.D. McKee, In vitro osteogenesis assays: influence of the primary cell source on alkaline phosphatase activity and mineralization, Pathol. Biol. 57 (2009) 318-323.

[56] J. Puls, S.A. Wilson, D. Holter, Degradation of Cellulose Acetate-based Materials: A review, J. Polym. Environ. 19 (2011) 152-165.

[57] P.C. Tseng, S.M. Hou, R.J. Chen, H.W. Peng, C.F. Hsieh, M.L. Kuo, M.L. Yen, Resveratrol promotes osteogenesis of human mesenchymal stem cells by upregulating RUNX2 gene expression via the SIRT1/FOXO3A axis, J. Bone Min. Res. 26 (2011) 25522563.

[58] M Shakibaei, C Buhrmann, A Mobasheri. Resveratrol-mediated SIRT-1 interactions with p300 modulate receptor activator of NF-kappaB ligand (RANKL) activation of NFkappaB signaling and inhibit osteoclastogenesis in bone-derived cells. Journal of Biological Chemistry, 286 (2011) 11492-11505.

[59] M.S. Kamath, S.S.S.J. Ahmed, M. Dhanasekaran, S.W. Santosh, Polycaprolactone scaffold engineered for sustained release of resveratrol: therapeutic enhancement in bone tissue engineering, Int. J. Nanomed. 9 (2014), 183-195. 
[60] Y. Li, S. Danmark, U. Edlund, A. Finne-Wistrand, X. He, M. Norgård, E. Blomén, K. Hultenby, G. Andersson, U. Lindgren, Resveratrol-conjugated poly- $\varepsilon$-caprolactone facilitates in vitro mineralization and in vivo bone regeneration, Acta Biomater. 7 (2011), 751-758.

[61] S.N. Makhija, P.R. Vavia, Controlled porosity osmotic pump-based controlled release systems of pseudoephedrine. I. Cellulose acetate as a semipermeable membrane, J. Control. Release, 89 (2003) 5-18.

[62] W.C. Lu, E. Pringa, L. Chou, Effect of magnesium on the osteogenesis of normal human osteoblasts, Magnes. Res. 30 (2017) 42-52.

\section{List of Figures}

Fig. 1 Schematic representation of the reaction sequence for the derivatization of cellulose acetate membranes with resveratrol

Fig. 2 Scanning electron microscopy for synthesized membranes

Fig. 3 The TGA and DTA spectra of the synthesized membranes

Fig. 4 FT-IR spectra of synthesized membranes (left) and detail on region $750-1500 \mathrm{~cm}^{-1}$ (right)

Fig. 5 XPS spectra of synthesized membranes

Fig. 6 High resolution XPS of carbon region

Fig. 7 High resolution XPS of oxygen region

Fig. 8 Retention of Bovine Serum Albumin, respectively Hemoglobin through synthesized membranes

Fig. 9 Water flows for synthesized materials 
Fig. 10 Fluorescent detection of actin (green) and vinculin (red) in MC3T3-E1 cells cultured in the presence of $\mathrm{Mg}-\mathrm{CA}$ and $\mathrm{Mg}-\mathrm{CA}-$ Res extraction media for $2 \mathrm{~h}$ and $24 \mathrm{~h}$; $\mathrm{B}$. Cell proliferation capacity of MC3T3-E1 pre-osteoblasts grown in the presence of $\mathrm{Mg}$ alloy extracts for 1, 3 and 5 days, as determined by MTT assay. Results are presented as means $\pm \mathrm{SD}(\mathrm{n}=3)$.

Fig. 11 A. Alkaline phosphatase activity normalized by total protein content exhibited by MC3T3-E1 cells grown in the presence of Mg-CA and Mg-CA-Res extraction media for 7 and 14 days (*p<0.05 vs. Mg-CA extraction media); B. Quantitative determination of extracellular matrix mineralization $(* \mathrm{p}<0.05$ vs. $\mathrm{Mg}-\mathrm{CA}$ extraction media $+\mathrm{OM} ; * * * \mathrm{p}<0.001$ vs. Mg-CA extraction media $+\mathrm{OM})$. Results are presented as means $\pm \mathrm{SD}(\mathrm{n}=3)$. 


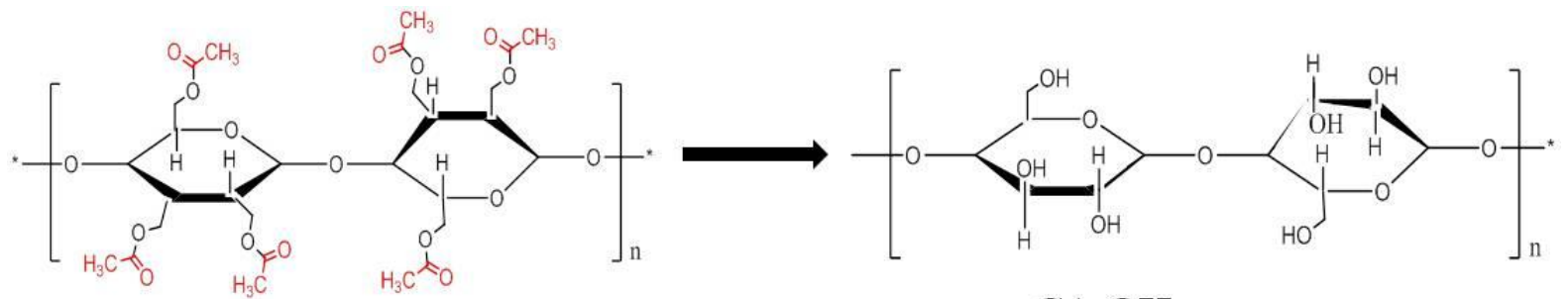

CA

CA-OH

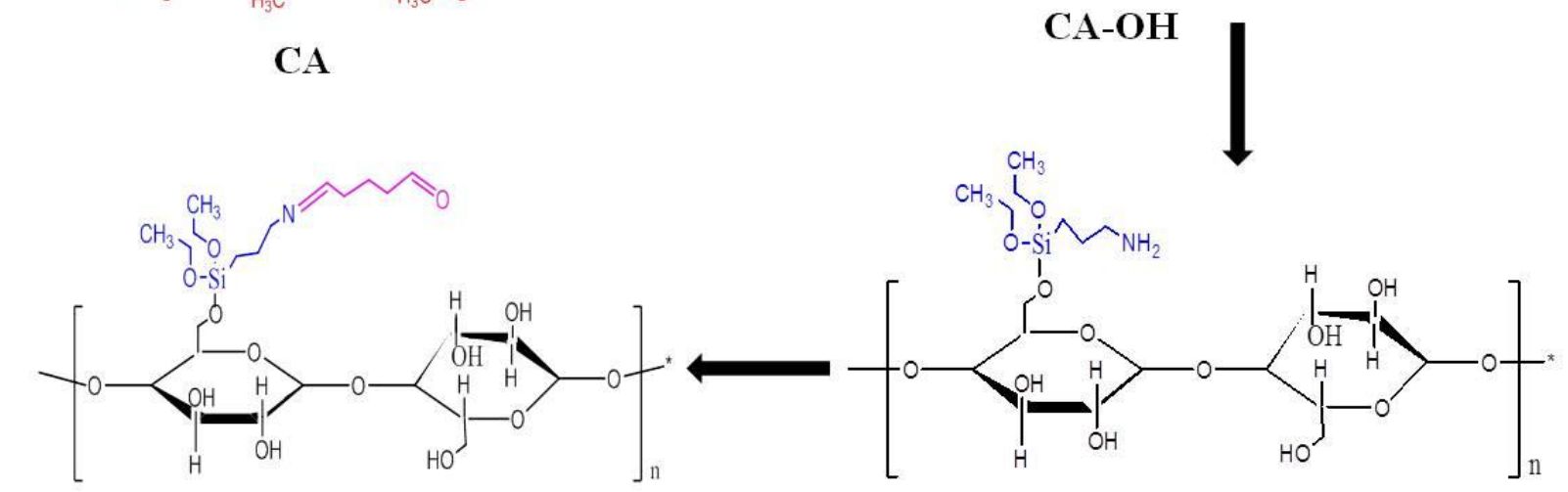

CA-APTS-GA

CA-APTS

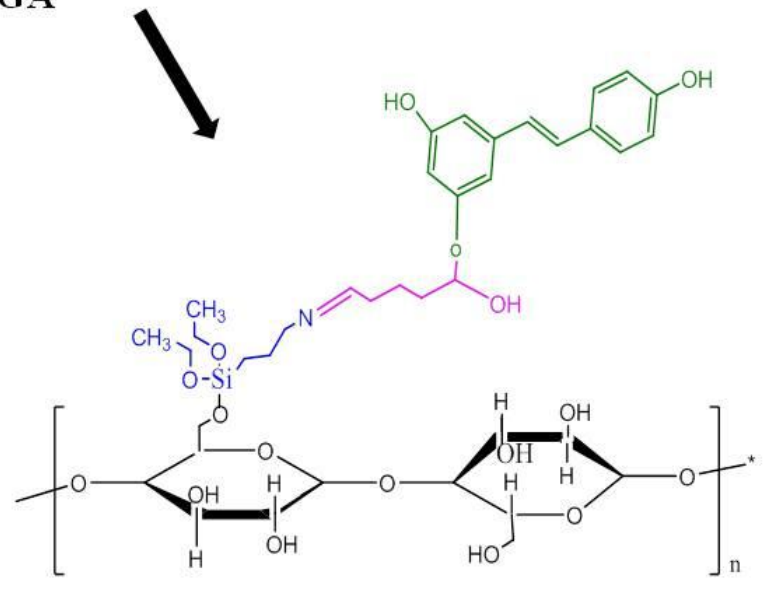

CA-APTS-GA-Res

Fig. 1 Schematic representation of the reaction sequence for the derivatization of cellulose acetate membranes with resveratrol 


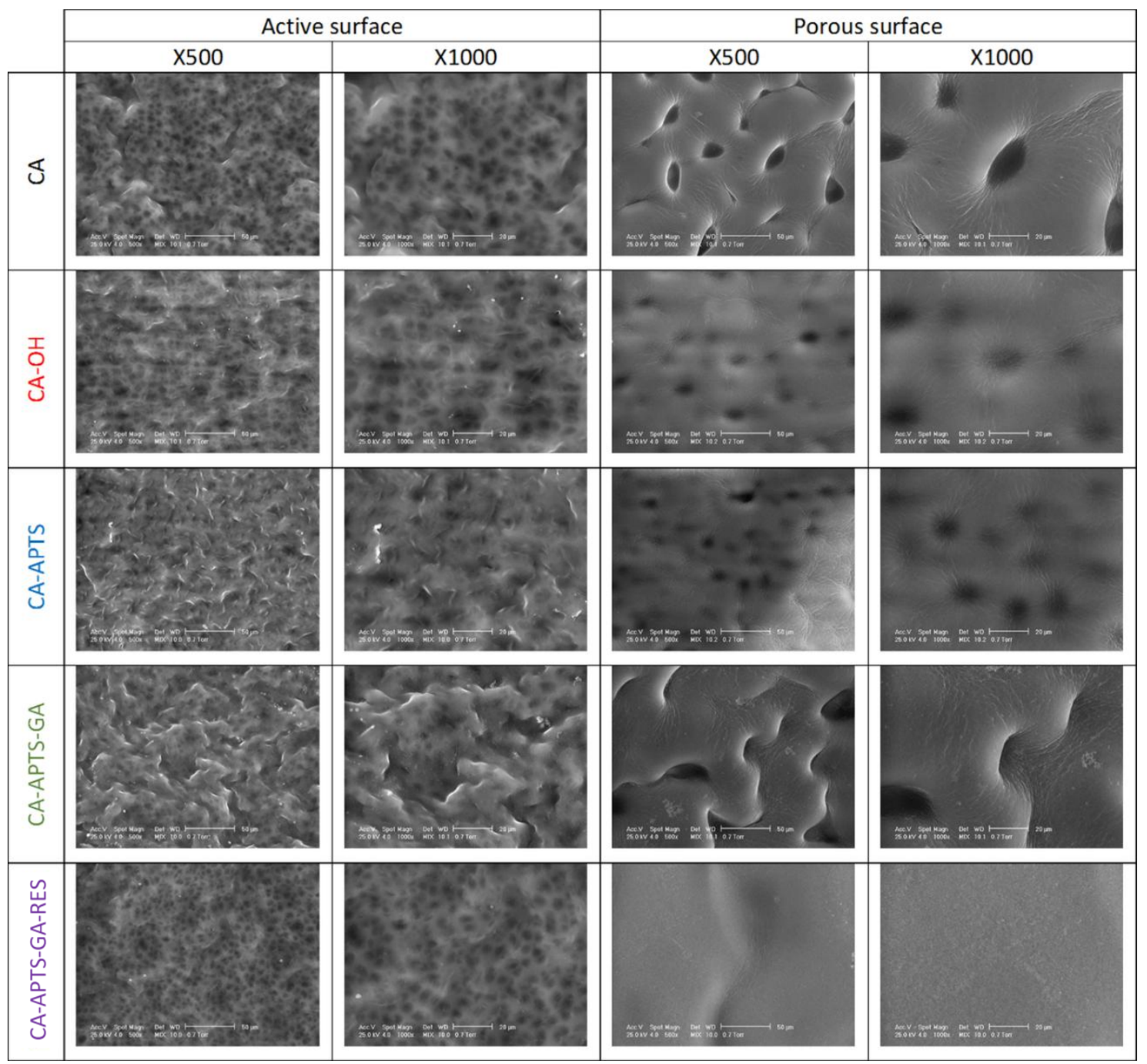

Fig. 2 Scanning electron microscopy for synthesized membranes 

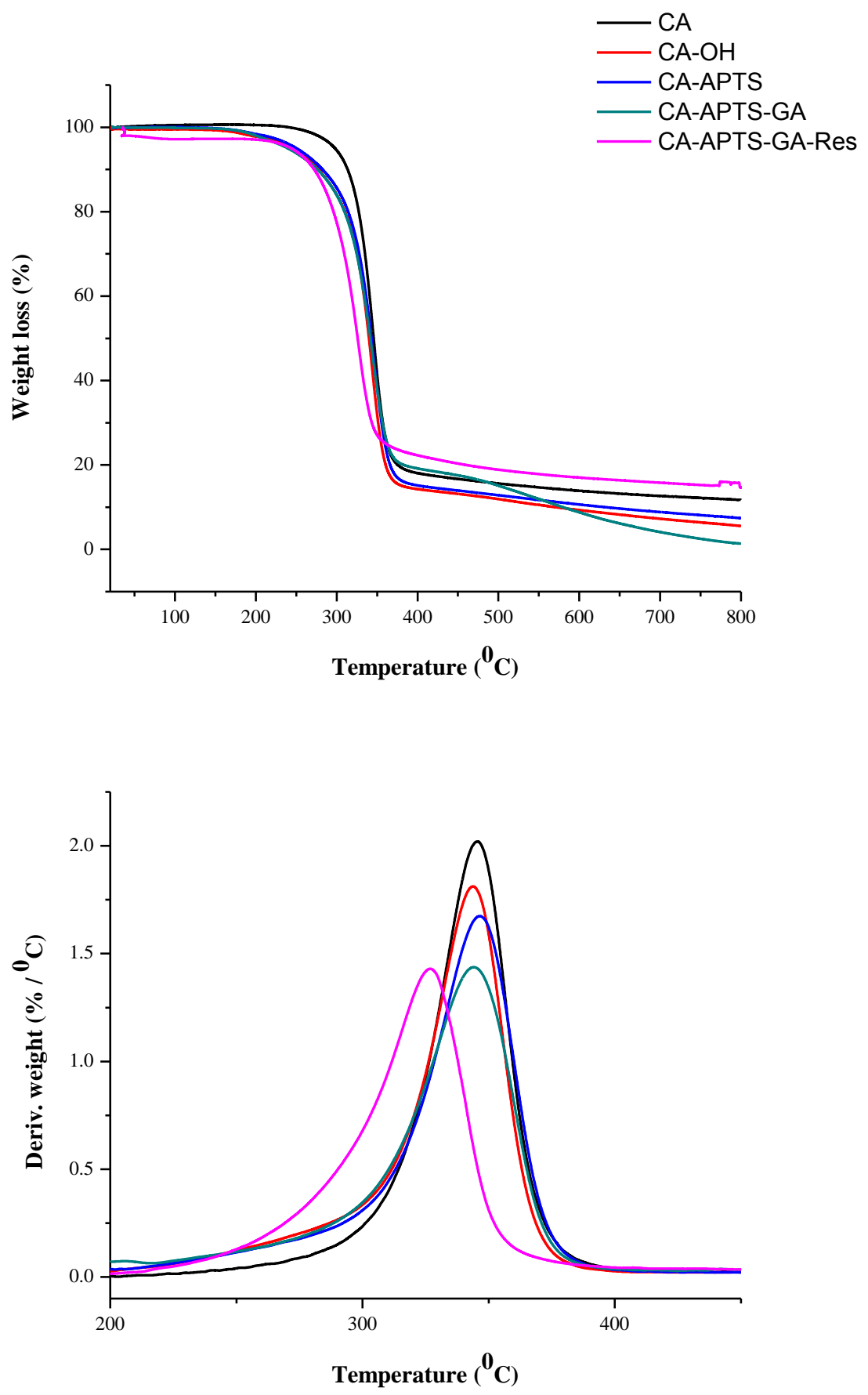

Fig. 3 The TGA and DTA spectra of the synthesized membranes 

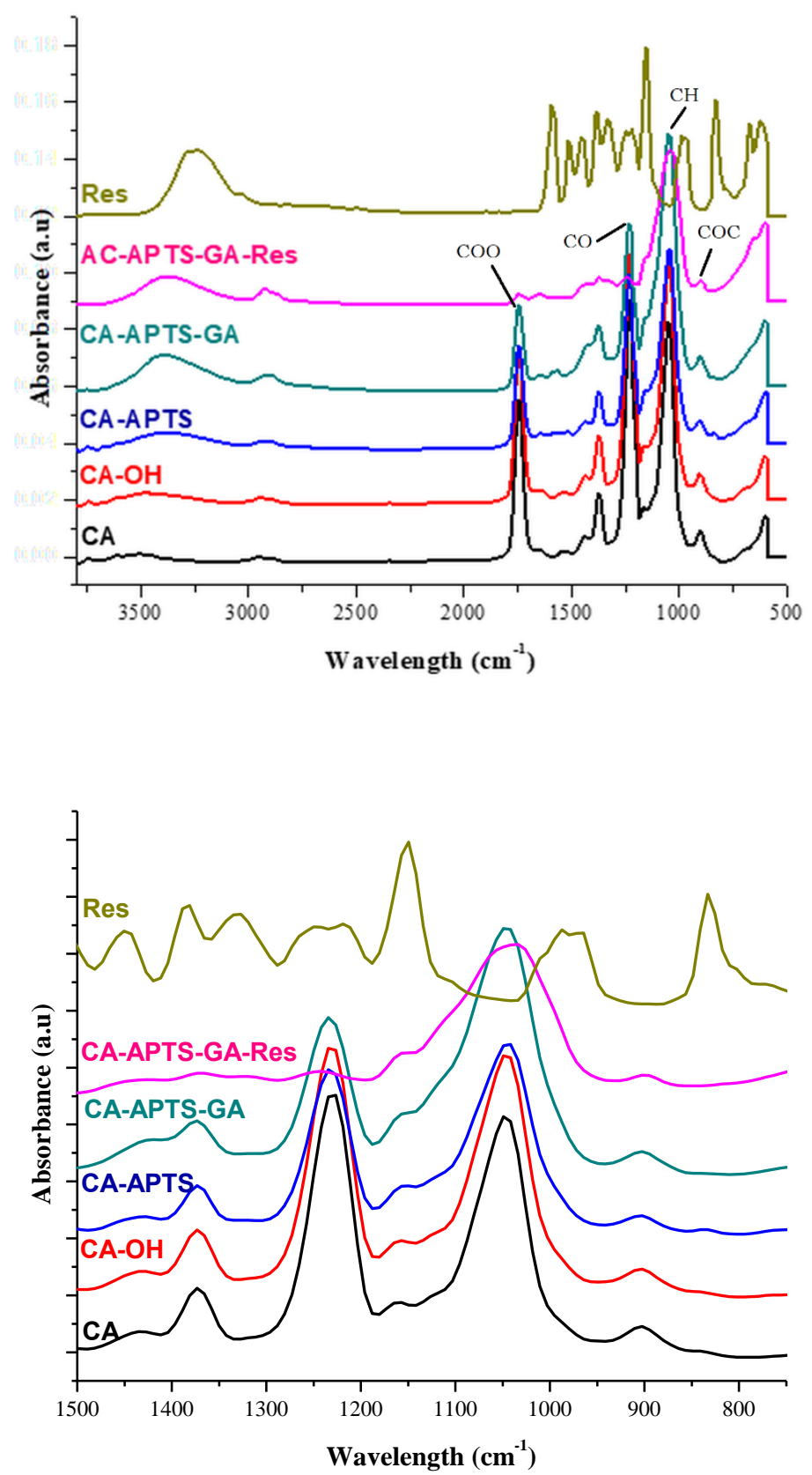

Fig. 4 FT-IR spectra of synthesized membranes (left) and detail on region $750-1500 \mathrm{~cm}^{-1}$ (right) 


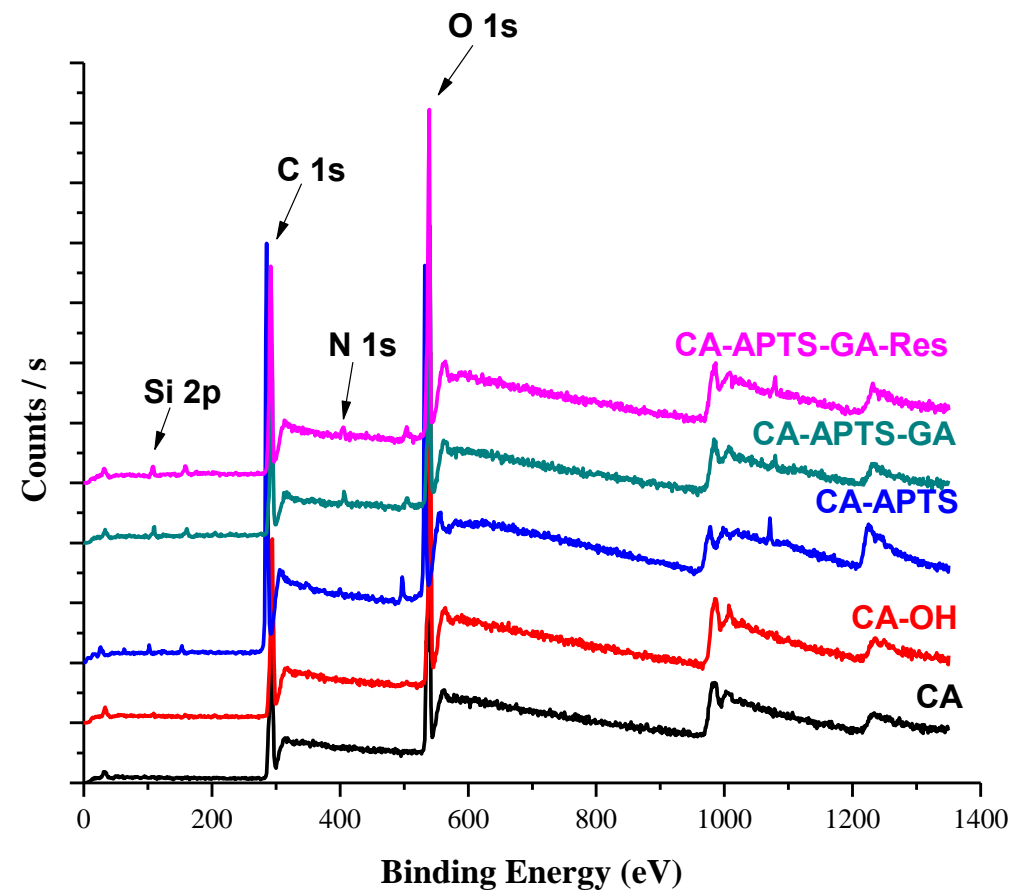

Fig. 5 XPS spectra of synthesized membranes 
C1s Scan
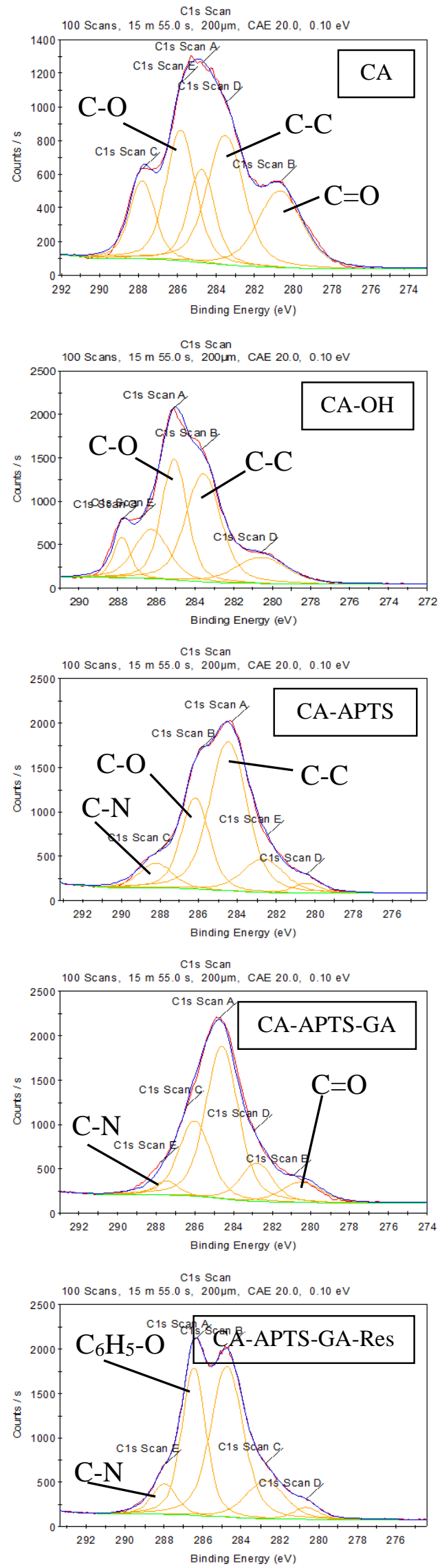
Fig. 6 High resolution XPS of carbon region
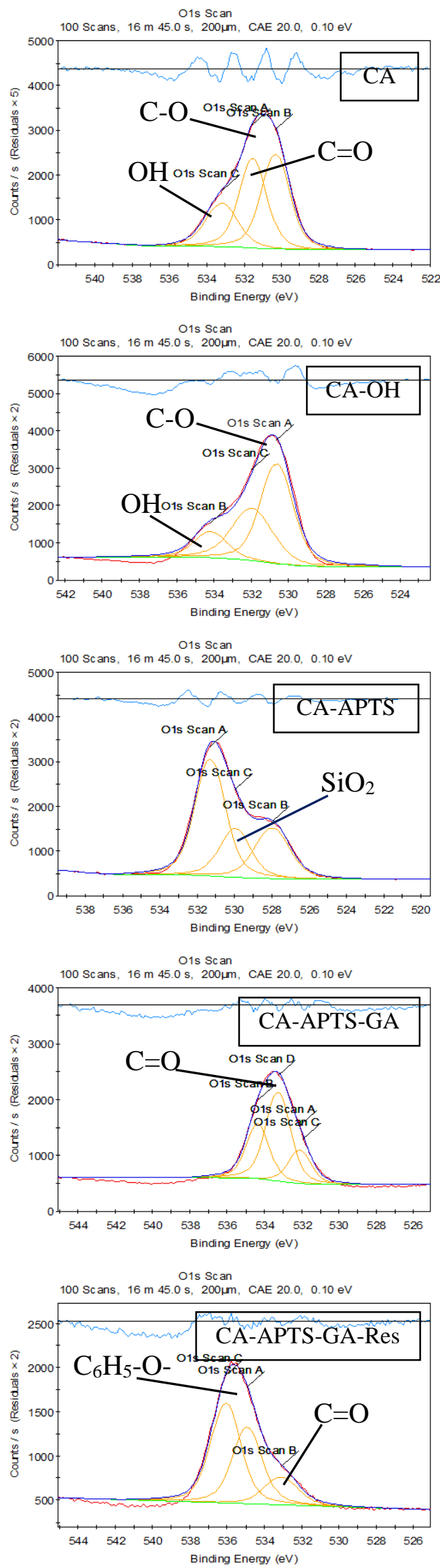
Fig. 7 High resolution XPS of oxygen region
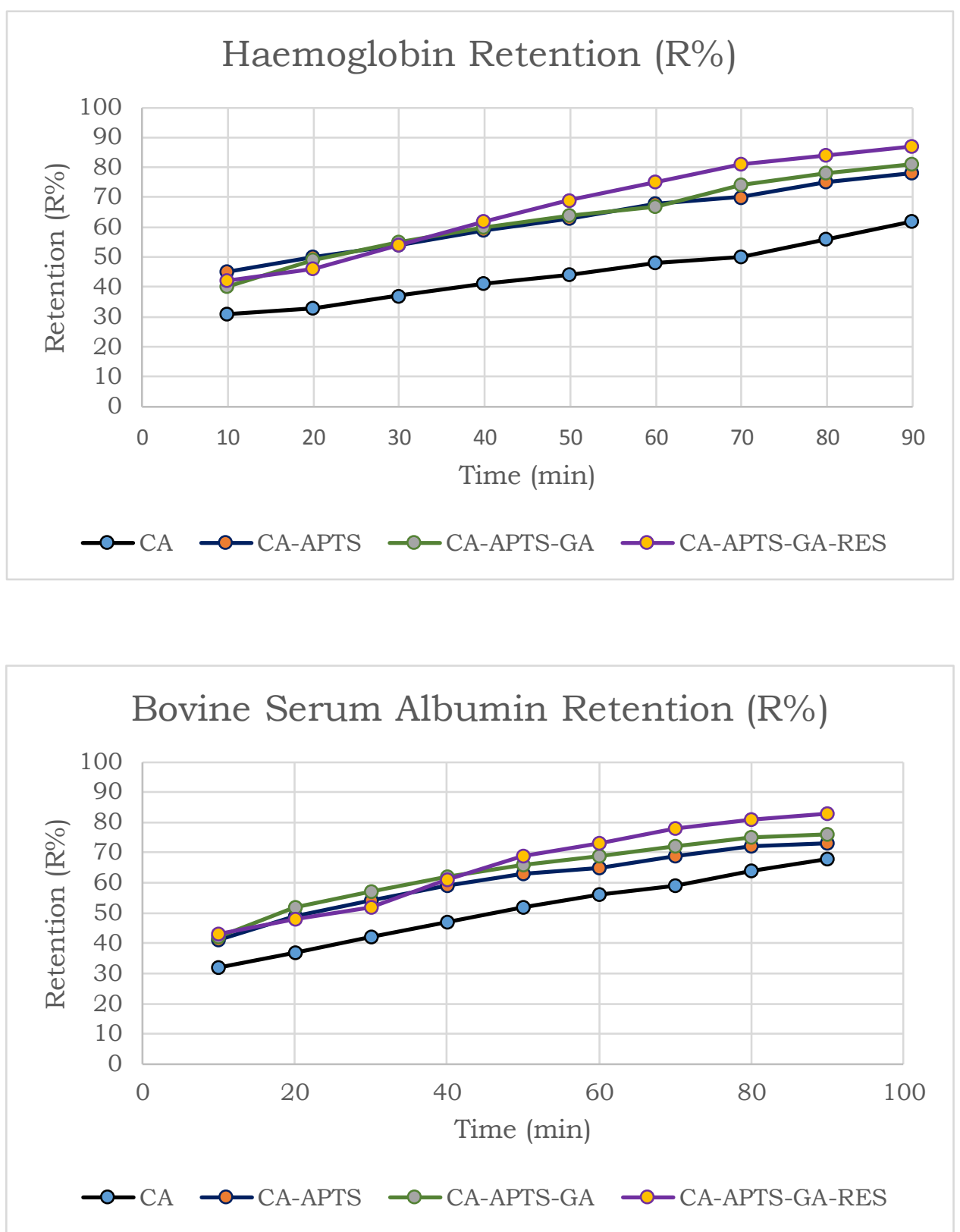

Fig. 8 Retention of Bovine Serum Albumin, respectively Hemoglobin through synthesized membranes 
Water flows

12000

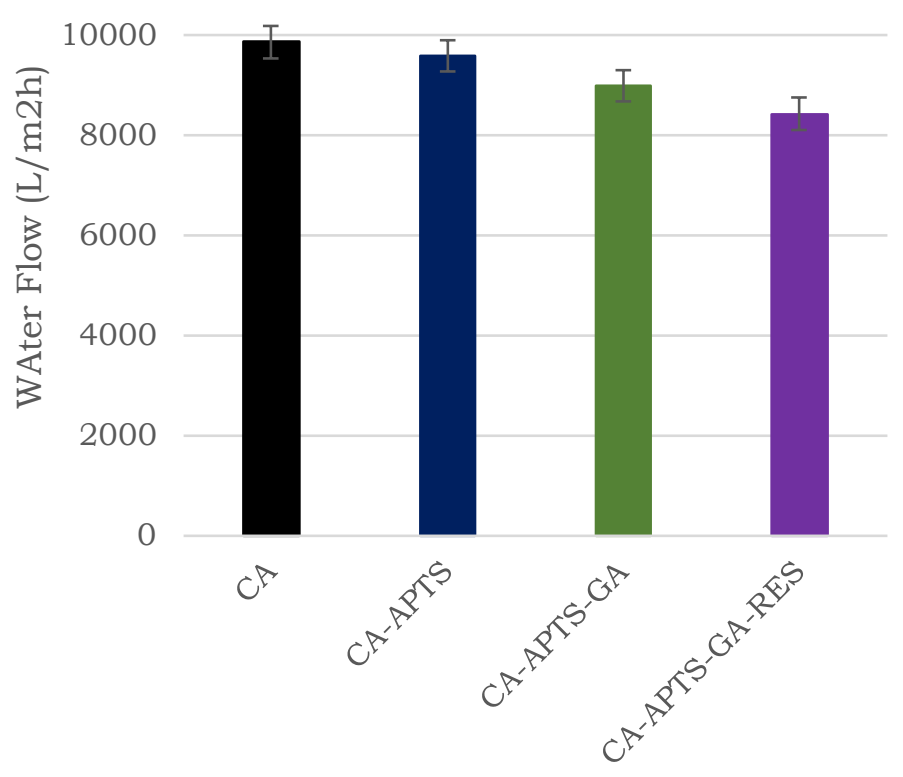

Fig. 9 Water flows for synthesized materials 

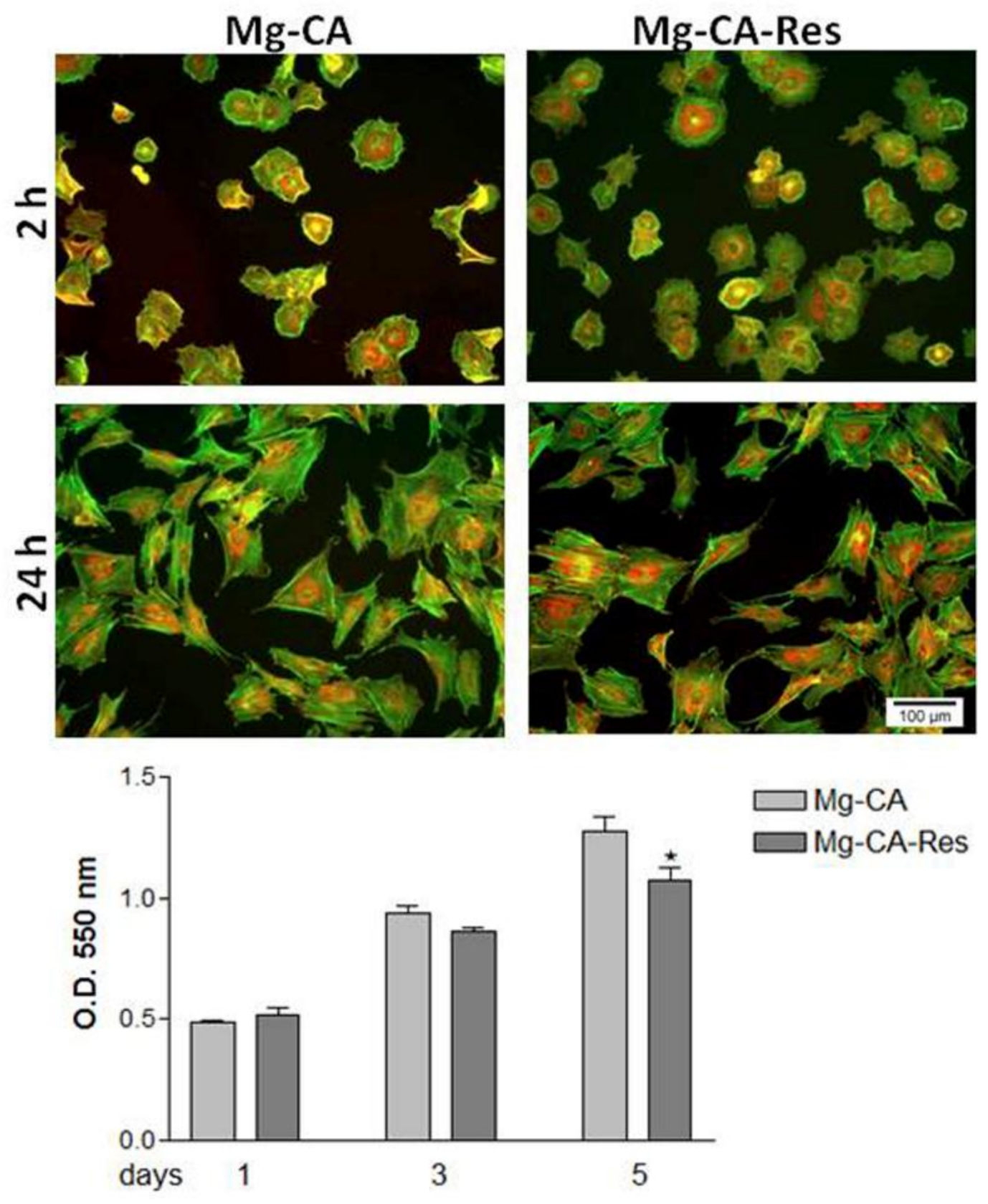

Fig. 10. Fluorescent detection of actin (green) and vinculin (red) in MC3T3-E1 cells cultured in the presence of Mg-CA and Mg-CA-Res extraction media for $2 \mathrm{~h}$ and $24 \mathrm{~h}$; $\mathrm{B}$. Cell proliferation capacity of MC3T3-E1 pre-osteoblasts grown in the presence of $\mathrm{Mg}$ alloy extracts for 1, 3 and 5 days, as determined by MTT assay. Results are presented as means $\pm \mathrm{SD}(\mathrm{n}=3)$. 


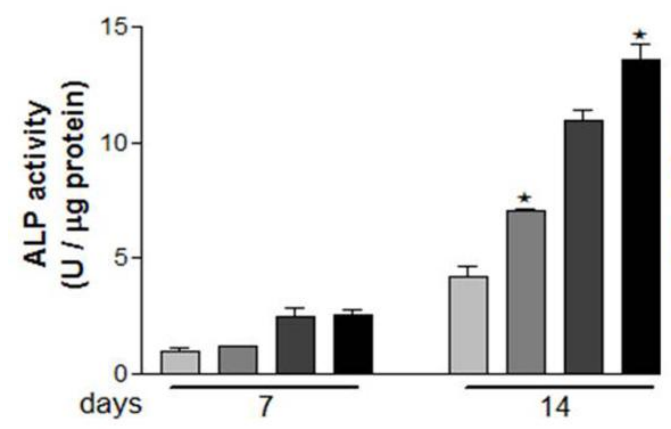

A

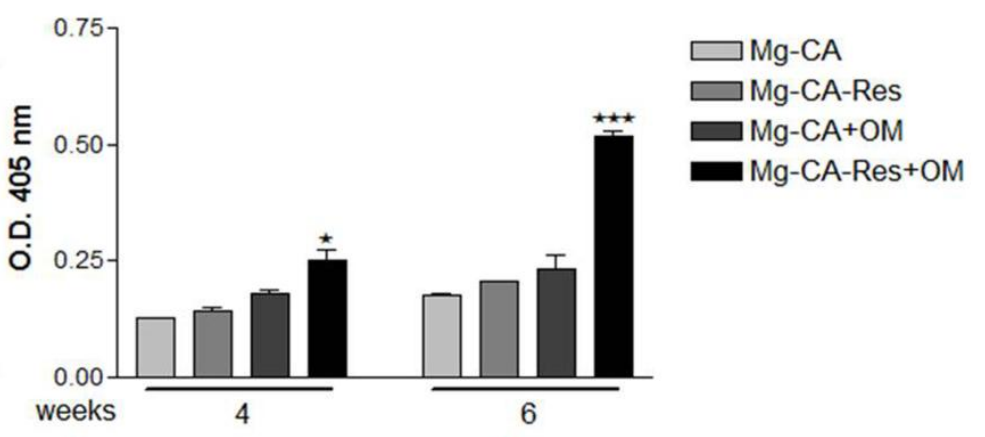

B

Fig. 11. A. Alkaline phosphatase activity normalized by total protein content exhibited by MC3T3-E1 cells grown in the presence of Mg-CA and Mg-CA-Res extraction media for 7 and 14 days ( $* \mathrm{p}<0.05$ vs. Mg-CA extraction media); B. Quantitative determination of extracellular matrix mineralization $(* \mathrm{p}<0.05$ vs. Mg-CA extraction media $+\mathrm{OM} ; * * * \mathrm{p}<0.001$ vs. Mg-CA extraction media $+\mathrm{OM})$. Results are presented as means $\pm \mathrm{SD}(\mathrm{n}=3)$. 
Table 1 Td3\% DTG values for the synthesized membranes

\begin{tabular}{|l|l|l|}
\hline Membranes & Td3\% & DTG \\
\hline CA & 286 & 345 \\
\hline CA-OH & 221 & 344 \\
\hline CA-APTS & 229 & 346 \\
\hline CA-APTS-GA & 214 & 344 \\
\hline CA-APTS-GA-RES & 204 & 327 \\
\hline
\end{tabular}




\section{Highlights}

Cellulose acetate membranes can be used for biomedical applications

Surface modification with resveratrol can be successfully carried out using a coupling agent Membranes performances can be improved by functionalization

Resveratrol can improve the Osseointegration properties of cellulose acetate membranes 
2018-11-13

\section{Cellulose acetate membranes}

\section{functionalized with resveratrol by} covalent immobilization for improved osseointegrat

Pandele, A. M.

Elsevier

Pandele AM, Neacsu P, Cimpean A, et al., Cellulose acetate membranes functionalized with resveratrol by covalent immobilization for improved osseointegration. Applied Surface Science, Volume 438, 30 April 2018, pp. 2-13

https://doi.org/10.1016/j.apsusc.2017.11.102

Downloaded from Cranfield Library Services E-Repository 